\title{
Mínimo existencial e reserva do possível nas demandas de saúde e as consequências para o princípio da igualdade
}

Minimum existential and possible reserve in health lawsuits and the consequences for the principle of equality

Mínimo existencial y reserva posible en las demandas de salud y las consecuencias para el principio de igualdad

\section{Resumo}

A Constituição Federal de 1988 estabeleceu um Estado social, garantindo direitos entendidos como essenciais que seriam suportados pela coletividade, entre eles, o direito social à saúde. Sem embargo, a disponibilidade financeiroorçamentária do Estado não é suficiente para oferecer plenamente a garantia dos direitos sociais a todos. Nesse contexto antinômico exsurgem as demandas judiciais, momento em que a discussão remete à garantia do Estado ao mínimo existencial a uma vida digna e o princípio da reserva do possível. Ademais, no momento em que se concede determinado medicamento, individualmente, por meio de decisão judicial, acaba-se por contornar os critérios de igualdade estabelecidos para a política de saúde pública no Brasil. Isto posto, o presente estudo aborda o Estado em seu aspecto político, como garantidor de direitos, com enfoque no fornecimento de medicamentos. Para isso, resgatou-se, por meio de pesquisa exploratória documental, os conceitos de mínimo existencial e reserva do possível, perfazendo uma análise quanto aos impactos para o princípio da igualdade, visando evitar controvérsias a respeito da prevalência ao direito à saúde. Ao final, verificou-se que o Poder Público tem as ferramentas necessárias para otimizar a gestão dos recursos e aperfeiçoar a efetividade constitucional.

Palavras-chave: Direitos sociais; Reserva do possível; Igualdade; Saúde.

\begin{abstract}
The Federal Constitution of 1988 established a social state, guaranteeing rights understood as essential that would be supported by the community, among them, the social right to health. However, the budgetary availability of the State is not sufficient to fully guarantee social rights for all. In this antinomic context lawsuits emerge, a moment in which the discussion refers to the guarantee of the State to the minimum existential to a dignified life and the principle of possible reserve. Furthermore, when a certain drug is granted, individually, through a court decision, it ends up circumventing the criteria of equality established for the public health policy in Brazil. That said, the present study addresses the State in its political aspect, as a guarantor of rights, with a focus on the supply of medicines. For this purpose, the concepts of minimum existential and possible reserve were rescued, through exploratory documentary research, making an analysis of the impacts for the principle of equality, aiming to avoid controversies regarding the prevalence of the right to health. In the end, it was found that the Public Power has the necessary tools to optimize the management of resources and improve constitutional effectiveness.
\end{abstract}

Keywords: Social rights; Possible reserve; Equality; Health.

\section{Resumen}

La Constitución Federal de 1988 estableció un estado social, garantizando derechos entendidos como esenciales que serían apoyados por la comunidad, incluido el derecho social a la salud. Sin embargo, la disponibilidad financieropresupuestaria del Estado no es suficiente para garantizar plenamente los derechos sociales de todos. En este contexto antinómico surgen los juicios, momento en el que la discusión se refiere a la garantía estatal del mínimo existencial a una vida digna y al principio de la reserva de lo posible. Además, cuando una determinada droga es otorgada, individualmente, a través de una decisión judicial, termina eludiendo los criterios de igualdad establecidos para la política de salud pública en Brasil. Dicho esto, este estudio aborda al Estado en su vertiente política, como garante de 
derechos, con foco en el suministro de medicamentos. Para ello, se rescataron los conceptos de mínimo existencial y reserva de lo posible, a través de una investigación documental exploratoria, realizando un análisis sobre los impactos sobre el principio de igualdad, con el objetivo de evitar controversias sobre la prevalencia del derecho a la salud. Al final, se verificó que el Poder Público cuenta con las herramientas necesarias para optimizar la gestión de los recursos y mejorar la efectividad constitucional.

Palabras clave: Derechos sociales; Reserva como sea posible; Igualdad; Salud.

\section{Introdução}

A Constituição Federal de 1988 deu início a um novo "contrato social" da sociedade brasileira. A Constituição cidadã estabeleceu um Estado elementarmente social, garantindo direitos entendidos como essenciais que seriam suportados pela coletividade.

Direitos sociais constitucionalmente estabelecidos são um avanço importante na história brasileira. Classificados como direitos fundamentais de segunda geração ou dimensão (Bobbio, 2004, p. 8), os direitos sociais, assim como os direitos e garantias fundamentais, possuem aplicação imediata, sendo que encontram-se enumerados exemplificativamente no Capítulo II do Título II do texto constitucional, e não esgotam os direitos fundamentais constitucionais que se encontram difusamente previstos na própria Constituição Federal (Moraes, 2016, p. 350).

Nesse sentido, o artigo $6^{\circ}$ da Carta Magna fixa como direitos sociais garantidos a todo brasileiro "a educação, a saúde, a alimentação, o trabalho, a moradia, o transporte, o lazer, a segurança, a previdência social, a proteção à maternidade e à infância, a assistência aos desamparados" (Brasil, 1988), dentre os quais moradia, alimentação e transporte foram ampliados posteriormente, respectivamente, nos anos de 2000, 2010 e 2015.

José Afonso da Silva (2014, p. 560) classifica as normas constitucionais de acordo com sua eficácia, sendo as mesmas categorizadas como "plenas", "contidas" ou "limitadas". Isto posto, a efetivação dos direitos no rol do artigo $6^{\circ}$ da Carta Magna clama por implantação de políticas públicas para sua concretização, condicionando a classificação do referido artigo como de eficácia limitada, declaratória e de princípio programático.

Nesse contexto, também coaduna a norma programática do artigo 196 da Constituição Federal ao estabelecer que:

Art. 196 - A saúde é direito de todos e dever do Estado, garantido mediante políticas sociais e econômicas que visem à redução do risco de doença e de outros agravos e ao acesso universal e igualitário às ações e serviços para sua promoção, proteção e recuperação (Brasil, 1988) [grifo meu].

É possível concluir, à vista disso, que a implementação da garantia à saúde se condiciona à criação de políticas públicas fixadas em lei, exigindo uma conduta positiva do Estado, de natureza prestacional, e, de outro lado, resultando, para a população, em um aguardo indefinido pelas ações efetivas dos Poderes Executivo e Legislativo.

Lenza (2019, p. 1608) leciona que a dignidade da pessoa humana demanda a garantia mínima de alguns direitos, entendidos aqui como o núcleo do mínimo existencial. Da mesma forma, Barroso (2010, p. 26-27) explana que, dentro da eficácia jurídica dos princípios constitucionais, são incluídos, no mínimo existencial, os direitos "à educação fundamental, à saúde básica, à assistência aos necessitados e ao acesso à justiça” todos compreendidos dentro do princípio da dignidade da pessoa humana.

A efetividade de direitos está intrinsecamente relacionada à disponibilidade de recursos financeiros do Estado destinados à causa, surgindo, portanto, a teoria da reserva do possível, tema abordado no terceiro capítulo deste artigo. Diante disso, somente a intervenção judicial será o instrumento apto a dirimir o conflito entre a não prestação pelo Estado de determinada garantia constitucional e o direito subjetivo violado frente ao preceito petrificado também na Carta Maior.

O fornecimento de medicamentos por via judicial contorna os critérios de igualdade estabelecidos para a política de saúde pública no Brasil. Nesse sentido, este estudo visa investigar se a garantia ao mínimo existencial à saúde por meio de demandas judiciais fere ou viola o princípio da igualdade, especificamente nas demandas relativas ao fornecimento de 
medicamentos. Portanto, o estudo resgata os conceitos de mínimo existencial e reserva do possível, perfazendo uma análise quanto aos impactos para o princípio da igualdade, a fim de relativizar a aparente controvérsia a respeito da prevalência do direito à saúde e da dignidade da pessoa humana.

\section{Metodologia}

Metodologicamente, o estudo consistiu em pesquisa documental exploratória (Gil, 2019) referente ao objeto em tela, de natureza qualitativa, com a utilização de autores renomados do direito constitucional bem como da legislação aplicável para a compreensão dos conceitos que sustentam os princípios ora analisados, apurando-se, assim, o entendimento jurisprudencial hodierno na resolução do problema em questão. Adicionalmente, foram resgatados conceitos dos filósofos Immanuel Kant e John Rawls para se compreender os critérios adotados pelo constituinte originário, admitindo-se no neocontratualismo político erigido pela filosofia desses autores, aquilo que há de moderno na compreensão racional do Direito, notadamente no constitucionalismo, e sua aplicabilidade contemporânea.

No primeiro capítulo deste artigo fora abordado o mínimo existencial, construindo um entendimento do porquê os direitos sociais estarem previstos na Constituição, sua relação com a dignidade da pessoa humana e com a equidade enquanto justiça. Abordou-se o critério de justiça de John Rawls para demonstrar que a equidade na garantia de direitos sociais é resultante de lógica, mesmo na visão de um autor politicamente liberal.

No segundo capítulo, por sua vez, procedeu-se ao estudo da teoria da reserva do possível, resgatando sua origem histórica internacional e como é possível entender os limites de sua aplicação dentro do ordenamento jurídico brasileiro.

No terceiro capítulo, dentro do pretenso recorte metodológico, abordou-se a questão da igualdade no acesso à saúde, elencando a forma como o ordenamento busca assegurar esse princípio e quais os critérios de incorporação e acesso aos tratamentos disponibilizados pelo Sistema Único de Saúde, conforme disciplinado pela Lei no 8.080/90, especificamente quanto ao fornecimento de determinados medicamentos não previstos nos Protocolos Clínicos de Diretrizes Terapêuticas.

Derradeiramente, no quarto capítulo, é realizada uma análise das demandas judiciais por medicamentos, os critérios definidos pelo Superior Tribunal de Justiça (STJ), o excesso de judicialização e como isso impacta no planejamento e execução do orçamento público.

\section{Resultados e Discussão}

\section{1 - Mínimo existencial como critério de justiça}

O propósito basilar de um determinado país possuir uma constituição escrita é limitar o poder político do Estado. A incorporação de direitos na Carta Maior torna estes direitos dispensáveis do reconhecimento do legislador ordinário (Moraes, 2016, p. 91). Isto posto, a construção histórica dos direitos fundamentais do homem culminou por incorporar na Constituição de 1988 a positivação e consolidação dos direitos fundamentais sociais, previstos no Capítulo II do Título II da norma máxima da República.

Moraes (2016, p. 349) leciona que os direitos sociais estão subordinados à regra da autoaplicabilidade, prevista no $\S 1^{\circ}$, do art. $5^{\circ}$ da Constituição Federal, estando suscetíveis ao "ajuizamento do mandado de injunção, sempre que houver a omissão do poder público na regulamentação de alguma norma que preveja um direito social e, consequentemente, inviabilize seu exercício".

Portanto, as regras fixadas na Carta Maior impõem uma corresponsabilidade social para com a garantia dos direitos sociais, independentemente de os ventos políticos levarem a administração da máquina pública para um viés mais neoliberal.

Outro ponto que deve o Estado observar para a efetivação dos direitos é a dignidade da pessoa humana. Luiz Roberto Barroso (2010, p. 15) explana que a dignidade é parte do conteúdo dos direitos fundamentais, não é um direito fundamental em 
si, mas um parâmetro de ponderação.

Cumpre destacar que a dignidade da pessoa humana é um dos fundamentos da República Federativa do Brasil $\left(\mathrm{CF}, 1^{\circ}\right.$, III), e "construir uma sociedade livre, justa e solidária” está elencada entre seus objetivos fundamentais (CF, $3^{\circ}$, I). Portanto, é para isso que o Estado foi constituído, fundado na dignidade e objetivando a justiça.

Barroso (2010, p. 4) expõe que a dignidade da pessoa humana tem origem religiosa, mas que, com o Iluminismo e a centralidade do homem, contemporaneamente encontra-se baseada na filosofia e fundamenta-se na razão, na capacidade de valoração moral e na autodeterminação do indivíduo.

Importante ressaltar a contribuição filosófica de Kant na noção de dever e razão, dois pontos que devem ser observados para compreender a inclusão dos direitos sociais na Constituição Federal de 1988, bem como a garantia da dignidade da pessoa humana através do mínimo existencial. Afinal, “a filosofia kantiana foi integralmente construída sobre as noções de razão e de dever, e sobre a capacidade do indivíduo de dominar suas paixões e de identificar, dentro de si, a conduta correta a ser seguida" (Barroso, 2010, p. 16).

Nesse sentido, não se pode olvidar das lições de Kant (2005, p. 64), nas quais a dignidade está acima de qualquer preço que possa ser atribuído, sendo ela um fim em si mesma, constituindo valor intrínseco do ser humano:

No reino dos fins, tudo tem um preço ou uma dignidade. Quando uma coisa tem preço, pode ser substituída por algo equivalente; por outro lado a coisa que se acha acima de todo o preço, e por isso não admite nenhuma equivalência, compreende uma dignidade.

Sob esse prisma, a dignidade da pessoa humana somente estará garantida se um conjunto de direitos mínimos também efetivamente o estiver, direitos estes que constituem o núcleo mínimo existencial (Lenza 2019, p. 1608).

Segundo Barroso (2010, p. 26), o mínimo existencial compreende direitos sem os quais não é possível a pessoa ser verdadeiramente livre, igual e capaz de exercer sua cidadania, considerados indispensáveis à sua existência física e psíquica. São esses os direitos à educação fundamental, à saúde básica, à assistência aos necessitados e ao acesso à justiça.

Em verdade, as políticas públicas de educação, saúde e assistência social, bem como o acesso à justiça, têm como objetivo universalizar aos cidadãos uma vida digna e plena, promovendo uma sociedade mais justa e igualitária. Conforme disserta Afonso da Silva (2020, p. 828) a ordem social, como um todo, forma "[...] com o título dos direitos fundamentais o núcleo substancial do regime democrático instituído".

Em que pese, não se pretenda neste momento retomar toda a discussão do conceito de justiça, infere-se que, para os fins deste artigo, trata-se de uma questão de equidade, pois o constituinte, ao atribuir à República o dever de garantir a dignidade e os direitos nela compreendidos, adotou postura similar ao teorizado por John Rawls.

Rawls (2000, p. 13) aborda a constituição de uma sociedade garantidora de liberdades fundamentais e, após isso, a distribuição maximizadora aos menos favorecidos. Para determinar os critérios de justiça são usadas as noções da "posição original” e do "véu da ignorância". Na posição original, o autor remete a um estado pré-contratual, em que as disposições do que é considerado justiça ainda não foram fixadas. Nesse momento, os “constituintes” devem fixar as regras da sociedade, e, para tanto, é necessário o véu da ignorância.

O véu da ignorância é um exercício mental em que aquele que está a fixar as regras para a sociedade desconhece o papel que tomará nela. Caso fosse diferente, a tendência humana de priorizar suas próprias necessidades seria um obstáculo adicional à obtenção da justiça. Sua classe social, religião, raça, gênero, se possui alguma deficiência, ou mesmo o acesso a recursos naturais, tudo é uma incógnita na nova sociedade que se forma. Portanto, os critérios fixados devem ser os que garantam a vida livre e digna de toda a sociedade, sem preterir qualquer parcela ou segmento (Rawls, 2000, p.13).

O professor Ricardo Perlingeiro Mendes da Silva (1998, n.p.), tratando da Teoria da Justiça de John Rawls, reforça que: 
A teoria da justiça pressupõe uma teoria do bem, mas dentro de limites amplos. Tais limites não prejudicam a escolha do tipo de pessoas que os sujeitos querem ser. Uma vez deduzidos os princípios de justiça, a teoria contratualista fixa limites à concepção do bem, que decorrem da prioridade da justiça sobre a eficiência e da prioridade da liberdade sobre os benefícios sociais e econômicos [grifo meu].

Assim, mesmo em uma visão liberal, os ditames do que seria a justiça estão devidamente fixados no contrato social que fixou o que é considerado justo e equânime, quais são os limites da liberdade e o que deve o Poder Público realizar para garantir essa justiça. Para a sociedade brasileira: a Constituição Federal de 1988.

É nessa leitura que pode ser observado que o núcleo do mínimo existencial remete ao critério de justiça no qual se alicerça o Estado, operando de modo a garantir a dignidade da pessoa humana, independentemente do segmento da sociedade a que pertence.

Nesse contexto é que surge o entendimento de que o Poder Público não pode permanecer indiferente às questões sociais, qualquer que seja a esfera institucional de sua atuação, como, por exemplo, a problemática da saúde da população, “sob pena de incidir, ainda que por censurável omissão, em grave comportamento inconstitucional” (Lenza, 2019, p. 2051).

No entanto, é cediço que todo direito fundamental tem um custo, seja uma prestação positiva ou negativa a ser realizada pelo Estado, devendo o gestor da máquina pública administrar a escassez de recursos ao fazer escolhas alocativas orçamentárias (Mendes \& Branco, 2015, p. 643).

Ademais, embora o problema econômico da escassez ocorra diante de recursos finitos e necessidades infinitas, o núcleo dos direitos essenciais ${ }^{1}$ constitui uma necessidade finita e determinada, alterando somente a forma de sua satisfação (Pereira, 2014, p. 41-46). Significa dizer que a saúde básica é uma demanda humana fixa e universal, variando apenas a forma de sua satisfação em virtude da disponibilidade técnica, financeira e até mesmo cultural.

Sendo assim, a implementação de qualquer política social está condicionada faticamente à disponibilidade de recursos estatais e é nesse sentido que o Estado tem alegado a "reserva do possível”, justificando que não há condições financeiras para custear de maneira plena os direitos sociais estabelecidos, tema que será abordado no capítulo seguinte.

\subsection{Reserva do possível e seus limites}

O conceito de reserva do possível surgiu primeiramente na Alemanha, no ano de 1972, em um caso conhecido como numerus clausus, envolvendo o acesso ao curso superior de medicina, cujas vagas eram limitadas pelo Estado. No referido caso, a corte alemã entendeu que, embora não houvesse vagas disponíveis para todos os interessados, o Estado estava empregando esforços no sentido de ampliação da capacidade dos cursos, sendo assim, estariam os cidadãos limitados à oferta de vagas dentro daquilo que é razoavelmente possível (Pereira, 2014, p. 23-24).

Pereira (2014, p. 41) aponta, ainda, que a teoria da reserva do possível foi concebida com a nítida intenção de tornar legítima a ausência estatal perante as demandas pleiteadas pelos cidadãos. Isto pois as necessidades humanas, que deveriam ser asseguradas, superam os recursos disponíveis ao Estado, inviabilizando a plena satisfação simultânea de todas as necessidades.

No Brasil, a primeira aplicação judicial deste conceito se deu no ano de 2003, no julgamento da Intervenção Federal $n^{\circ}$ 2.915 (0001552-34.2001.0.01.0000), em que atuou como relator o ministro Gilmar Mendes. O caso aludia ao pagamento de precatórios pelo Estado de São Paulo, no entanto, o ministro atentara para os limites financeiros e as obrigações estatais, ressaltando, ainda, a reserva do financeiramente possível ao lembrar que o exercício de determinados direitos depende de pressuposto fático.

\footnotetext{
${ }^{1}$ Embora os direitos sociais sejam uma demanda crescente em busca de melhores condições de vida e uma necessidade indeterminada pela própria indeterminação social em sua diversidade de carências, trata-se aqui dos direitos compreendidos no mínimo existencial, que incluem tão somente os direitos à educação fundamental, à saúde básica, à assistência aos necessitados e ao acesso à justiça.
} 
O assunto, todavia, já era discutido desde meados dos anos 90 e foi tomando forma com o passar dos anos. O caso, no Estado de Santa Catarina, que originou a Petição n ${ }^{\circ} 1.246$ SC foi paradigma para a questão. Ele envolvia a demanda de tratamento de alto custo para uma criança, no qual se discutia um procedimento a ser realizado nos Estados Unidos para uma paciente com Síndrome de Duchene. A doença é considerada rara e o tratamento à época custaria cerca de R \$ 85.500,00 (oitenta e cinco mil e quinhentos reais) (Pereira, 2014, p.36). No referido caso prevaleceu o direito à saúde, destacando-se no voto do ministro Celso de Mello três aspectos: I) a doença ser rara; II) o tratamento ser imprescindível para o autor; III) "a impostergabilidade do cumprimento do dever constitucional do Estado para com a saúde, que é direito de todos" (Pereira, 2014, p. 36).

Apenas em 2004, sem embargo, na Arguição de Descumprimento de Preceito Fundamental n. 45 (ADPF 45), que o relator ministro Celso de Mello pavimentou a base para aplicação da reserva do possível de forma limitada, afirmando que o Estado não pode invocar tal cláusula sem que haja um justo motivo objetivamente aferível. Nesse diapasão, o ônus de provar que deve ser aplicada a reserva do possível é exclusivamente do Estado, não havendo qualquer hipótese de inversão desta dinâmica (Lazari, 2016, p. 61).

Para o acolhimento ou não da teoria da reserva do possível, é basilar que se observe a demanda trazida em juízo; se a mesma procura atender à necessidade humana, ou à necessidade humana fundamental ${ }^{2}$ (Pereira, 2014, p. 46). Isso, pois, conforme voto do relator ministro Celso de Mello na ADPF 45, ao Estado não é lícito:

[...] exonerar-se do cumprimento de suas obrigações constitucionais, notadamente quando, dessa conduta governamental negativa, puder resultar nulificação ou, até mesmo, aniquilação de direitos constitucionais impregnados de um sentido essencial fundamentalidade. (Brasil, 2004)

Por outro lado, a aplicação da teoria da reserva do possível implica entender que o Estado está realizando o razoavelmente esperado para satisfazer os direitos sociais constitucionalmente petrificados. Nesse sentido, em um cenário ideal, afasta-se a responsabilidade do ente estatal para com as demandas judiciais, pois o mesmo estaria empregando todo o esforço possível para o cumprimento das obrigações constitucionalmente programadas, não havendo que se falar em omissão governamental.

Portanto, fundamental se faz ponderar que os direitos sociais são direitos de "satisfação progressiva", sob o enfoque de que, embora seja inviável a sua realização integral, o Estado deve envidar esforços no planejamento para possibilitar uma realização tanto contínua quanto progressiva das prestações (Pereira, 2014, p. 59).

Importante destacar que esse esforço progressivo e consequente adoção da teoria da reserva do possível pode ser evidenciado na própria Constituição Federal (Brasil, 1988), quando dispõe sobre como os orçamentos devem ser planejados e geridos, estabelecendo percentuais mínimos de aplicação para saúde e educação:

Art. 195. A seguridade social será financiada por toda a sociedade, de forma direta e indireta, nos termos da lei, mediante recursos provenientes dos orçamentos da União, dos Estados, do Distrito Federal e dos Municípios, e das seguintes contribuições sociais:

$[\ldots]$

Art. 198. As ações e serviços públicos de saúde integram uma rede regionalizada e hierarquizada e constituem um sistema único, organizado de acordo com as seguintes diretrizes:

I - no caso da União, a receita corrente líquida do respectivo exercício financeiro, não podendo ser inferior a $15 \%$ (quinze por cento);

$[\ldots]$

\footnotetext{
${ }^{2}$ Como observado no capítulo anterior, considera-se fundamentais os direitos compreendidos no mínimo existencial, sem os quais não há condições mínimas de garantia de dignidade e, portanto, o núcleo dos direitos essenciais configura-se como uma necessidade humana fundamental.
} 
Art. 212. A União aplicará, anualmente, nunca menos de dezoito, e os Estados, o Distrito Federal e os Municípios vinte e cinco por cento, no mínimo, da receita resultante de impostos, compreendida a proveniente de transferências, na manutenção e desenvolvimento do ensino.

$[\ldots]$

$\backslash \mathrm{Aq}$

Por força do $\S 3^{\circ}$ do artigo 198 da Constituição Federal, os percentuais de aplicação de recursos à saúde exigidos aos estados e municípios são fixados por lei complementar, atualmente vigorando doze por cento aos estados e quinze por cento aos municípios (Lei Complementar $n^{\circ} 141$, de 13 de janeiro de 2012, $\operatorname{artigos} 6^{\circ}$ e $7^{\circ}$ ).

Mas, afinal, como demonstrar que não é possível financeiramente implementar um direito?

Para Hinkelammert (Crítica à razão utópica, p. 20, apud Pereira, 2014, p. 72), o que é possível deve ser descoberto realisticamente, não podendo ser pré-determinado. Sendo assim, o Estado deveria, prima facie, empregar todos os esforços para a implementação das garantias constitucionais, e, apenas quando na aplicação fática resultar no insucesso, estaria demonstrada a impossibilidade.

Como pode ser observado, a teoria da reserva do possível encontra respaldo constitucional podendo, portanto, ser invocada, contudo, sua aplicação está limitada à demonstração aferível de prejuízo à coletividade, cujo ônus é exclusivo do Estado.

O conceito de mínimo existencial e reserva do possível, com efeito, frequentemente serão sopesados na dialética processual quando da demanda relativa à saúde, e, como visto, o primeiro possui melhores condições de prevalecer.

Sendo assim, cumpre ao próximo capítulo detalhar a questão da igualdade no acesso à saúde, como tal política trata a igualdade e se as decisões judiciais interferem nesse princípio constitucional.

\subsection{Igualdade na garantia do direito à saúde}

Visando garantir a igualdade no atendimento à saúde aos cidadãos, a Lei nº 8.080, de 19 de setembro de 1990, assim definiu como princípio:

Art. $7^{\circ}$ As ações e serviços públicos de saúde e os serviços privados contratados ou conveniados que integram o Sistema Único de Saúde (SUS), são desenvolvidos de acordo com as diretrizes previstas no art. 198 da Constituição Federal, obedecendo ainda aos seguintes princípios:

$[\ldots]$

IV - igualdade da assistência à saúde, sem preconceitos ou privilégios de qualquer espécie;

[...] (Brasil, 1990) [grifo meu].

Para que essa igualdade fosse assegurada, a referida Lei instituiu o Protocolo Clínico de Diretrizes Terapêuticas (PCDT), ferramenta burocrática que visa garantir a impessoalidade e uniformidade no tratamento, assim definido pelo inciso II do artigo 19-N:

[...] documento que estabelece critérios para o diagnóstico da doença ou do agravo à saúde; o tratamento preconizado, com os medicamentos e demais produtos apropriados, quando couber; as posologias recomendadas; os mecanismos de controle clínico; e o acompanhamento e a verificação dos resultados terapêuticos, a serem seguidos pelos gestores do SUS (BRASIL, 1990).

Sendo assim, para a disponibilização de determinado medicamento, pretende a Lei restringir aos previamente analisados e incluídos aos PCDTs. Por consequência, a inclusão de novos medicamentos está por sua vez condicionada à competência do Ministério da Saúde, assessorado pela Comissão Nacional de Incorporação de Tecnologias no SUS (Conitec) (Lei nº 8.080/90, art. 19-Q, caput).

Salutar se faz observar que o Brasil adotou a Medicina Baseada em Evidências (MBE), e é nesse contexto que a 




I - as evidências científicas sobre a eficácia, a acurácia, a efetividade e a segurança do medicamento, produto ou procedimento objeto do processo, acatadas pelo órgão competente para o registro ou a autorização de uso;

II - a avaliação econômica comparativa dos benefícios e dos custos em relação às tecnologias já incorporadas, inclusive no que se refere aos atendimentos domiciliar, ambulatorial ou hospitalar, quando cabível (Brasil, 1990) [grifo meu].

A avaliação de tecnologia em saúde segue rigoroso processo para a incorporação de novo medicamento à rede pública, observando os aspectos da eficácia, segurança, efetividade além dos prováveis impactos social, organizacional, legal, ético e político do uso do fármaco analisado (Brasil, 2016, p. 9).

Devido à participação da comunidade ser uma das diretrizes do Sistema Único de Saúde, prevista na Lei nº 8.080/90, o procedimento de avaliação pode ser requisitado por qualquer interessado, sendo geralmente iniciado pela empresa fornecedora da nova tecnologia. Essa predominância da participação do fornecedor se dá, pois o protocolo de requisição de avaliação requer a apresentação de estudo científico prévio, e, em alguns casos, até mesmo amostras do produto objeto da análise.

A Comissão de Incorporação de Tecnologias realiza uma série de consultas públicas buscando opiniões de pacientes e contribuições técnico-científicas da comunidade médica. A Lei prevê também a realização de audiência pública para discussão dos resultados, contudo, "só ocorrerá se a relevância da matéria justificar o evento e deverá ser solicitada pelo Secretário de Ciência, Tecnologia e Insumos Estratégicos do Ministério da Saúde” (Brasil, 2016, p. 20)

De acordo com o artigo 19-R da Lei n ${ }^{\circ}$ 8.080/1990, ainda, o prazo de avaliação da comissão é cento e oitenta dias, prorrogável por mais noventa dias. Após a avaliação, o relatório da comissão é publicado na forma de portaria, contudo, o Ministério da Saúde possui um prazo de mais cento e oitenta dias para proceder à incorporação da tecnologia ao Sistema Único de Saúde (SUS), conforme artigo 25 do Decreto n ${ }^{\circ}$ 7.646, de 21 de dezembro de 2011.

Denota-se com isso que o procedimento de incorporação possui o prazo legal de um ano e três meses. Não se pode olvidar que durante esse período, o medicamento já se encontra com a sua comercialização autorizada aos particulares, com o devido registro na Anvisa. Ademais, o ínterim em evidência, somado ao prazo necessário para estudos e protocolização do pedido de análise, representam ao paciente, hipossuficiente de recursos, um tempo precioso em que o tratamento deixa de ser realizado.

Nessa sistematização, é comum que surjam novas tecnologias medicamentosas que custem a ser avaliadas e incluídas no PCDT, ou que podem se mostrar mais onerosas que as opções disponíveis, não prosperando no processo de disponibilização via Sistema Único de Saúde.

Apesar do sistema moroso, o propósito burocrático é justamente assegurar a padronização do tratamento despendido ao cidadão, garantindo a igualdade ao acesso aos recursos, a impessoalidade, e evitar a incidência de procedimento díspar. Em diversos casos, no entanto, as opções de tratamento disponibilizadas pelo Sistema Único de Saúde são esgotadas pelo paciente, se mostrando ineficazes para o caso concreto.

Cumpre observar que para os casos oncológicos são aplicadas Diretrizes Diagnósticas e Terapêuticas (DDT), que passam por uma análise semelhante realizada pela Conitec, porém possuem um sistema diferenciado de financiamento dos procedimentos, sendo este a principal distinção para com o PCDT. Esse sistema se materializa como repasses aos centros de atenção, que mantêm autonomia na escolha da melhor opção para cada situação clínica para o procedimento de tratamento disponível nestes centros.

Ademais, algumas doenças não possuem um protocolo clínico definindo, hipótese em que em que será aplicado o artigo 19-P da Lei n ${ }^{o}$ 8.080/90, disponibilizando ao paciente o fármaco receitado, desde que este integre uma das relações de medicamentos instituídas pelos gestores de qualquer das três esferas de poder. Portanto, em muitos casos, o tratamento demandado, essencial para a qualidade de vida ou sobrevivência do cidadão, não estará disponível no SUS. 
É nesse contexto que surgem as demandas judiciais para a obtenção de medicamentos de alto custo, de tal maneira que o Supremo Tribunal Federal (STF) tece críticas quanto ao excesso de judicialização, asseverando que esta causa prejuízo direto às políticas públicas (Notícias STF, 2020).

Além do PCDT, outra ferramenta que assegura a igualdade é o próprio direito de ação, uma vez que a Constituição garante em seu artigo $5^{\circ}, \mathrm{XXXV}$, que "a lei não excluirá da apreciação do Poder Judiciário lesão ou ameaça a direito", assegurando a igualdade esculpida no caput do mesmo artigo.

Assim, o cidadão possui também o facultas exigire, o direito de exigir do Estado a prestação positiva do direito à saúde. O professor Fredie Didier Jr. (2018, p. 219) salienta ainda que "o direito de ação é o direito a uma jurisdição qualificada; direito a uma jurisdição tempestiva, adequada e efetiva".

Com efeito, não se pode limitar a judicialização das demandas relativas à obtenção de fármacos, pois, estando presente a lesão ou ameaça a direito é assegurado ao cidadão que busque a intervenção do Poder Judiciário para garantir a eficácia do direito constitucionalmente previsto.

Sendo assim, a igualdade estaria assegurada no direito abstrato de ação, na medida em que oportuniza a possibilidade da apreciação judicial àqueles com seu direito material à saúde ameaçado. Isto posto, as demandas judiciais e seus critérios relativos ao fornecimento de medicamentos serão abordados no capítulo subsequente.

\subsection{Demandas judiciais relativas à saúde}

Para entender as demandas relativas à saúde, primeiramente é essencial entender que esta pode ser dividida em cinco categorias: saúde preventiva; saúde restauradora; saúde pós-restabelecimento; saúde experimental; e demais questões atinentes à saúde. Nessa leitura, as três primeiras formas são entendidas como pertencentes ao mínimo existencial, pois estão contidas no entendimento de saúde básica (Lazari, 2016, p. 130-131).

Nesse sentido, a busca pela intervenção judicial para a garantia da eficácia Constitucional do direito à saúde levou o Superior Tribunal de Justiça a formular o Tema 106 (BRASIL, 2018), fixando critérios para o fornecimento de medicamentos nessas demandas:

A concessão dos medicamentos não incorporados em atos normativos do SUS exige a presença cumulativa dos seguintes requisitos:

i) Comprovação, por meio de laudo médico fundamentado e circunstanciado expedido por médico que assiste o paciente, da imprescindibilidade ou necessidade do medicamento, assim como da ineficácia, para o tratamento da moléstia, dos fármacos fornecidos pelo SUS;

ii) incapacidade financeira de arcar com o custo do medicamento prescrito;

iii) existência de registro do medicamento na ANVISA, observados os usos autorizados pela agência.

Tese definida no acórdão dos embargos de declaração publicado no DJe de 21/9/2018 (RE 566471 RG, Relator(a): MARCO AURÉLIO, Tribunal Pleno, julgado em 15/11/2007, DJe-157 DIVULG 06-12-2007 PUBLIC 07-12-2007 DJ 07-12-2007 PP-00016 EMENT VOL-02302-08 PP-01685)

Destaca-se que a imprescindibilidade do medicamento demandado, bem como a ineficácia dos fármacos fornecidos pelo SUS, são demonstradas no processo via laudo médico que aponte os tratamentos utilizados que resultaram ineficazes. Há de se considerar, porém, que o ente demandado, por muitas vezes, exige do paciente o total esgotamento das alternativas previstas no PCDT, para que de fato não haja dúvida quanto a ineficácia de tratamentos disponíveis pela rede pública.

Por sua vez, a incapacidade financeira é uma exigência pertinente que merece apontamentos. O primeiro deles é que, embora a prestação à saúde seja garantia constitucional e universal, a jurisprudência tem se fixado no sentido de que, para o sucesso da demanda jurisdicional, o requerente deve comprovar que a aquisição do medicamento é demasiadamente onerosa à sua situação econômica: 
CONSTITUCIONAL E ADMINISTRATIVO. DIREITO À SAÚDE. FORNECIMENTO DE MEDICAMENTO. LEGITIMIDADE PASSIVA DOS ENTES DA FEDERAÇÃO. ADEQUAÇÃO E NECESSIDADE. HIPOSSUFICIÊNCIA NÃO CONFIGURADA. HONORÁRIOS. 1) União, estados e municípios são responsáveis solidários pelo fornecimento de prestações relacionadas à saúde. 2) Faz jus ao fornecimento de medicamento o paciente que comprova a necessidade e a adequação de uso por meio da prova pericial. 3) A princípio, a hipossuficiência financeira do paciente não é requisito para a concessão ou não de prestação de saúde. Entretanto, o autor não pode ser considerado hipossuficiente para fins de prestação de medicamentos, em face do seu amplo patrimônio e ao baixo custo do medicamento requerido. 4) Afastada a condenação em litigância de má-fé e de restituição dos valores em face da revogação da liminar. 5) Honorários advocatícios mantidos no valor fixado. (TRF4, AC 500073032.2010.404.7208, Quarta Turma, relator Cândido Alfredo Silva Leal Júnior, juntado aos autos em 10.07.2015) [grifo meu]

Outro ponto que merece evidência é que a hipossuficiência não possui critério objetivo, sendo que devem ser sopesados os recursos do requerente em relação ao custo do medicamento pleiteado, como pode ser observado no julgado supra colacionado ${ }^{3}$.

Outrossim, a existência de registro na Anvisa atende aos critérios de segurança e eficácia da distribuição e utilização do medicamento em território nacional. Destaca-se que os tratamentos experimentais são descartados, pois não há justificativa para que se aplique recursos públicos em determinado procedimento ou medicamento que a ciência não foi capaz de assegurar a eficácia.

Nesse contexto, evidencia-se que o Brasil adotou a medicina baseada em evidências, portanto, para que o magistrado determine o fornecimento de um medicamento específico, o mesmo deve possuir o respectivo registro na Anvisa, que é o órgão responsável pela regulamentação dos fármacos no país.

Expostos os critérios estabelecidos pelo Superior Tribunal de Justiça, a grande questão que implica a incidência da teoria do mínimo existencial ao indivíduo indistintamente, é se a aplicação dos recursos não seria melhor realizada em favor da coletividade, e não em demandas individuais. Afinal, "por que adquirir remédios essenciais que não constem na lista do SUS, em lugar de investir na pesquisa científica sobre dadas doenças” (Pereira, 2014, p. 68).

A escassez deve ser administrada de tal modo que as escolhas não se tornem trágicas. Não deve o Poder Público criar virtualmente uma falta de recursos, proveniente de uma escolha política de prioridades, deixando bens jurídicos como a saúde e a vida desprotegidos. Assim, o que está em discussão não são os recursos alocados dentro da política de saúde, mas a concorrência destes recursos com políticas cujos fins não são considerados essenciais pela Constituição Federal ${ }^{4}$ (Pereira, 2014, p. 68-71).

A título de exemplo, a Secretaria de Saúde do Estado do Paraná publicou em 2018 estudo do impacto orçamentário decorrente de ordens judiciais que determinam o fornecimento de medicamentos. Segundo os dados apresentados foram expendidos respectivamente: 2013, $\mathrm{R} \$ 85.009 .327,63 ; 2014, \mathrm{R} \$ 90.417 .042,64 ; 2015, \mathrm{R} \$ 123.610 .396,41 ; 2016$, R\$ 164.760.191,86; e 2017, R \$ 194.797.661,50 (Pontarolli, Rossignoli, \& Moretoni, 2018).

No estudo de Pontarolli et al. (2018), o valor despendido com o fornecimento de fármacos por via judicial corresponde a 49\% do orçamento do Estado do Paraná destinado à aquisição de medicamentos, prejudicando assim o planejamento da saúde pública como um todo, uma vez que as aquisições determinadas pela justiça concorrem em recursos com a política de assistência farmacêutica, obstaculizando o planejamento e execução dessa política.

\footnotetext{
${ }^{3}$ As questões atinentes à prova da hipossuficiência não são revisitadas nos tribunais superiores por força da Súmula 7/STJ e da Súmula 279/STF, que vedam o reexame probatório. No entanto, pode ser observado que mesmo anteriormente à fixação do Tema 106 do STJ, a jurisprudência já coadunava com o entendimento de que a incapacidade financeira de arcar com o custo do medicamento prescrito depende do caso concreto, não havendo critério objetivo para a hipossuficiência de recursos e tampouco exigência de miserabilidade da parte demandante.

${ }^{4}$ Para a compreensão dos fins essenciais da Constituição Federal devem ser observados os objetivos fundamentais da República Federativa do Brasil, insculpidos no artigo $3^{\circ}$, e o conteúdo petrificado no Título II da Constituição Federal - Dos Direitos e Garantias Fundamentais -, com priorização aos direitos abarcados no núcleo do mínimo existencial.
} 
Além disso, o Supremo Tribunal Federal já se pronunciou, quando do julgamento da Suspensão de Tutela Antecipada n $278 \mathrm{AL}$, em que o ministro Gilmar Mendes relata que "ao deferir uma prestação de saúde entre as políticas sociais e econômicas formuladas pelo Sistema Único de Saúde, o Judiciário não está criando política pública, mas apenas determinando seu cumprimento" (Brasil, 2010).

Naquela oportunidade, o relator evidenciara em seu voto a tensão gerada entre os Poderes quando da intervenção judicial no orçamento público:

O fato é que o denominado problema da "judicialização do direito à saúde" ganhou tamanha importância teórica e prática que envolve não apenas os operadores do direito, mas também os gestores públicos, os profissionais da área de saúde e a sociedade civil como um todo. Se, por um lado, a atuação do Poder Judiciário é fundamental para o exercício efetivo da cidadania, por outro, as decisões judiciais têm significado um forte ponto de tensão perante os elaboradores e executores das políticas públicas, que se vêem compelidos a garantir prestações de direitos sociais das mais diversas, muitas vezes contrastantes com a política estabelecida pelos governos para a área de saúde e além das possibilidades orçamentárias". (STF - STA: 278 AL, Relator: Min. GILMAR MENDES (Presidente), Data de Julgamento: 17/03/2010, Tribunal Pleno, Data de Publicação: DJe-076 DIVULG 29-04-2010 PUBLIC 30-04-2010 EMENT VOL-02399-01 PP00142)

Nessa senda, destaca-se o posicionamento do STF no julgamento do ARE 727864 PR (Brasil, 2014), em que o relator, ministro Celso de Mello assevera:

[...] a intervenção jurisdicional, justificada pela ocorrência de arbitrária recusa governamental em conferir significação real ao direito à saúde, tornar-se-á plenamente legítima (sem qualquer ofensa, portanto, ao postulado da separação de poderes), sempre que se impuser, nesse processo de ponderação de interesses e de valores em conflito, a necessidade de fazer prevalecer a decisão política fundamental que o legislador constituinte adotou em tema de respeito e de proteção ao direito à saúde.

Ademais, tal caso gerou paradigma na discussão, sendo que o cerne da lide deve sempre observar o bem jurídico protegido, afastando a aplicabilidade da cláusula da reserva do possível quando comprometer os direitos contidos no mínimo existencial, reverberando as palavras do eminente relator até hoje em demais sentenças judiciais:

[...] entre proteger a inviolabilidade do direito à vida e à saúde - que se qualifica como direito subjetivo inalienável a todos assegurado pela própria Constituição da República (art. $5^{\circ}$, caput, e art. 196) - ou fazer prevalecer, contra essa prerrogativa fundamental, um interesse financeiro e secundário do Estado, entendo, uma vez configurado esse dilema, que razões de ordem ético-jurídica impõem, ao julgador, uma só e possível opção: aquela que privilegia o respeito indeclinável à vida e à saúde humanas. (STF - ARE: 727864 PR, Relator: Min. CELSO DE MELLO, Data de Julgamento: 04/11/2014, Segunda Turma, Data de Publicação: ACÓRDÃO ELETRÔNICO DJe-223 DIVULG 12-112014 PUBLIC 13-11-2014)

Diante do exposto, percebe-se um entrelaçamento entre as decisões judiciais e o planejamento das políticas públicas para o fornecimento de medicamentos. A intervenção judicial visa simplesmente garantir a eficácia constitucional, devendo o ente estatal considerar os resultados das demandas em seu planejamento futuro, incorporando medicamentos ao rol de fármacos disponíveis pelo SUS, visando sua própria organização orçamentária, garantindo direito, além de evitar judicialização de demandas repetitivas.

Admitindo-se isso, observa-se que para melhor planejamento da política de saúde, cumpre tão somente ao Poder Público criar ferramentas de celeridade de ampliação do Protocolo Clínico de Diretrizes Terapêuticas, seja revisando os protocolos estabelecidos com menor intervalo, seja considerando as decisões repetitivas para ampliação dos fármacos fornecidos na rede pública. 


\section{Conclusão}

No desenvolver do presente trabalho verificou-se que a garantia do mínimo existencial é condição sine qua non para a dignidade da pessoa humana, fundamento da República Federativa do Brasil.

Da mesma forma, a garantia dos direitos sociais na Carta Magna constitui uma limitação do poder político, uma ordem de prestação ao Estado, pactuado pela sociedade como uma corresponsabilidade social de promoção de justiça.

A garantia ao mínimo existencial é consequência moral, ética e lógica, fruto da construção histórica de conquista de direitos. O critério de justiça de John Rawls e as noções de razão e dever de Kant elucidam o porquê dessa corresponsabilidade estar petrificada na Constituição Federal.

A teoria da reserva do possível possui recepção constitucional e aplicabilidade, porém, somente se sobressairá sobre o mínimo existencial se o Estado comprovar de maneira aferível o prejuízo para a coletividade.

Em que pese a política de saúde pública ter especificado critérios para assegurar igualdade, o direito à saúde não pode ser negligenciado, sendo o fornecimento de medicamentos por via judicial o meio para dar eficácia à garantia constitucional deste direito. Verificou-se, ainda, a igualdade garantida enquanto direito de ação, a qual fornece oportunidade para aqueles que se sentirem desamparados pela política pública de saúde.

Por estes fundamentos, a dignidade não pode ser comprometida pela morosidade da atualização dos Protocolos Clínicos de Diretrizes Terapêuticas, devendo o poder judiciário intervir e proceder à análise de cada caso concreto.

Além disso, o Superior Tribunal de Justiça fixou critérios para o fornecimento judicial de medicamentos, entre eles está a incapacidade financeira do requerente de arcar com o custo do medicamento prescrito, evidenciando que não se trata de uma questão de igualdade propriamente dita, mas sim de equidade e promoção de justiça social, nos termos da Constituição Federal.

Outrossim, observa-se que o Estado tem consumido significativos recursos para atender o fornecimento de medicamentos demandados por via judicial. Com efeito, além de comprometer o planejamento e execução da política pública de saúde, a mora na incorporação de novas tecnologias pelo Estado acaba por obstaculizar o pronto fornecimento de medicamentos, dificultando o acesso àqueles que destes necessitam.

Ademais, ao adotar tal postura, o Poder Público acaba por expender muito mais recursos ao passo que é necessário mover, adicionalmente, toda máquina judicial em demandas cujo resultado poderia ser previsível.

Fica evidenciado que, diante dos avanços das tecnologias medicamentosas, o Poder Público deve revisar os Protocolos Clínicos de Diretrizes Terapêuticas com maior celeridade, visando a incorporação dos fármacos que podem ser o último recurso daqueles que sofrem com alguma doença. Outra medida que poderia ser implementada pelo Estado é a incorporação de medicamentos fornecidos em demandas judiciais repetitivas, estabelecendo uma espécie de precedente administrativo, o qual agilizaria o fornecimento do fármaco aos necessitados, pouparia despesas judiciais aos cofres públicos e permitiria um melhor planejamento orçamentário.

Por fim, verifica-se que o Estado tem as ferramentas necessárias para assegurar maior eficácia constitucional ao direito social da saúde, gestão e planejamento na atualização dos Protocolos Clínicos de Diretrizes Terapêuticas, ferramentas estas que melhor assegurariam a dignidade a qual o Estado se funda e mais precisamente objetivaria a justiça social a qual o Estado se propõe.

Sugere-se, como futuro estudo, a abordagem mais específica das relações de medicamentos, investigando os critérios e métodos de inclusão de fármacos não previstos nos Protocolos Clínicos de Diretrizes Terapêuticas nas referidas relações. Ademais, também é possível uma melhor perscrutação na questão da escassez virtual de recursos, bem como a realização de um estudo quantitativo acerca dos recursos públicos despendidos nos processos judiciais relativos às demandas de fornecimento de medicamentos. 


\section{Referências}

Barroso, L. R. (2010). A Dignidade da Pessoa Humana no Direito Constitucional Contemporâneo: Natureza Jurídica, Conteúdos Mínimos e Critérios de Aplicação. Versão provisória para debate público. Mimeografado, dezembro de $2010.2 \mathrm{https} / / \mathrm{www} .1$ luisrobertobarroso.com.br/wpcontent/uploads/2010/12/Dignidade_texto-base_11dez2010.pdf.

Bobbio, N. (2004). A era dos direitos. Tradução de Carlos Nelson Coutinho. Rio de Janeiro: Elsevier.

Brasil. (1988). Constituição Federal (1988). Promulgada em 5 de outubro de 1988. http://www.planalto.gov.br/ccivil_03/constituicao/constituicao.htm.

Brasil. (2011). Decreto $n^{\circ}$ 7.646, de 21 de dezembro de 2011. Dispõe sobre a Comissão Nacional de Incorporação de Tecnologias no Sistema Único de Saúde e sobre o processo administrativo para incorporação, exclusão e alteração de tecnologias em saúde pelo Sistema Único de Saúde - SUS, e dá outras providências. http://www.planalto.gov.br/ccivil_03/_Ato2011-2014/2011/Decreto/D7646.htm.

Brasil. (2012). Lei Complementar $n^{\circ} 141$, de 13 de janeiro de 2012. Regulamenta o § 3o do art. 198 da Constituição Federal para dispor sobre os valores mínimos a serem aplicados anualmente pela União, Estados, Distrito Federal e Municípios em ações e serviços públicos de saúde; estabelece os critérios de rateio dos recursos de transferências para a saúde e as normas de fiscalização, avaliação e controle das despesas com saúde nas 3 (três) esferas de governo; revoga dispositivos das Leis nos 8.080, de 19 de setembro de 1990, e 8.689, de 27 de julho de 1993; e dá outras providências. http://www.planalto.gov.br/ccivil_03/leis/lcp/lcp141.htm.

Brasil. (1990). Lei $n^{\circ} 8.080$, de 19 de setembro de 1990. Dispõe sobre as condições para a promoção, proteção e recuperação da saúde, a organização e o funcionamento dos serviços correspondentes e dá outras providências. http://www.planalto.gov.br/ccivil_03/leis/18080.htm.

Brasil. (2016). Ministério da Saúde. Secretaria de Ciência, Tecnologia e Insumos Estratégicos. Departamento de Gestão e Incorporação de Tecnologias em Saúde. Entendendo a Incorporação de Tecnologias em Saúde no SUS: como se envolver [recurso eletrônico]. Brasília: Ministério da Saúde. http://bvsms.saude.gov.br/bvs/publicacoes/entendendo_incorporacao_tecnologias_sus_envolver.pdf.

Brasil. (2018) Superior Tribunal de Justiça. Tema 106. Publicado no DJe de https://processo.stj.jus.br/repetitivos/temas_repetitivos/pesquisa.jsp?novaConsulta=true\&tipo_pesquisa=T\&cod_tema_inicial=106\&cod_tema_final=106.

Brasil. (2014). Supremo Tribunal Federal. Recurso Extraordinário com Agravo 727.864 PR. Relator: Min Celso de Mello. http://portal.stf.jus.br/processos/detalhe.asp?incidente=4346937.

Brasil. (2004). Supremo Tribunal Federal. Arguição de Descumprimento de Preceito Fundamental $n^{o} 45$. Relator: Min Celso de Mello. http://www.stf.jus.br/arquivo/informativo/documento/informativo345.htm.

Brasil. (2003). Supremo Tribunal Federal. Intervenção Federal $n^{o} \quad 2.915 . \quad$ Relator: Min Gilmar Mendes. https://jurisprudencia.stf.jus.br/pages/search/sjur13885/false.

Brasil. (2010). Supremo Tribunal Federal. Suspensão de Tutela Antecipada $n^{o} 278$ AL. Tribunal Pleno. Relator: Min. Gilmar Mendes (Presidente). Data de Julgamento: 17 mar 2010. Publicado no DJe-076 em 30 abr. 2010.

Brasil. (2015). Tribunal Regional Federal 4ª Região, Quarta Turma. Apelação Cível 5000730-32.2010.404.7208. Relator: Cândido Alfredo Silva Leal Júnior. Juntado aos autos em 10.07.2015.

Da Silva, J. A. (2020). Curso De Direito Constitucional Positivo. (43ª . Ed.): Ed. Jus Podivm.

Da Silva, J. A. (2014). Teoria do conhecimento constitucional. São Paulo: Malheiros Editores.

Didier Jr, F. (2018). Curso de direito processual civil: introdução ao direito processual civil, parte geral e processo de conhecimento. (20a . Ed.): Ed. Jus Podivm.

Gil, A. (2019). Métodos e técnicas de pesquisa social. (7ª ed.): Atlas.

Kant, I. (2005) Fundamentação da Metafísica dos Costumes e outros escritos. Tradução por Leopoldo Holzbach. São Paulo: Martin Claret.

Lazari, R. J. N. de. (2016). Reserva do Possível e mínimo existencial: a pretensão de eficácia da norma constitucional em face da realidade. (2 ${ }^{\text {a }}$ edição): Juruá.

Lenza, P. (2019). Direito constitucional esquematizado. (23ª . ed.) Edição Digital: Saraiva Educação.

Mendes, G. F., \& Branco, P. G. G. (2015). Curso de direito constitucional. - (10ª ed.) rev. e atual. Edição Digital: Saraiva.

Moraes, A. de. (2016). Direito constitucional. (32a. ed.) rev. e atual. até a EC nº 91, de 18 de fevereiro de 2016. Edição Digital. São Paulo: Atlas.

Pereira, A. L. P. (2014). Reserva do Possível: Judicialização de políticas públicas e jurisdição constitucional. Curitiba: Juruá.

Pontarolli, D., Rossignoli, P., \& Moretoni, C. (2018). Panorama da Judicialização de Medicamentos na Secretaria Estadual de Saúde do Paraná. 1ª Edição Conselho Nacional de Secretários de Saúde - CONASS. https://goo.gl/hiBn6L.

Rawls, J. (2000). Uma Teoria da Justiça. tradução Almiro Pisetta e Lenita M. R. Esteves. São Paulo: Martins Fontes.

Silva, R. P. M. da. (1998). Teoria da justiça de John Rawls. Revista CEJ, 2(6), 103-118. https://www2.senado.leg.br/bdsf/item/id/496870.

Notícias STF. (2020). Estado não é obrigado a fornecer medicamentos de alto custo não registrados na lista do SUS (atualizada). 11 mar. 2020. stf.jus.br/portal/cms/verNoticiaDetalhe.asp?idConteudo=439095. 